\title{
DEFENSA AMBIENTAL, DERECHOS HUMANOS Y ECOGENOETNOCIDIO AFROCOLOMBIANO
}

\author{
Santiago Arboleda Quiñonez ${ }^{1}$
}

\begin{abstract}
Resumen
El artículo destaca la necesidad de comprender la destrucción neo-extractivista que se está presentando en el pacifico colombiano y en otras partes del planeta, como un patrón integral, para ello propone la noción de ecogenoetnocidio. Destacando la defensa ambiental de las comunidades afrocolombianas, desde los mandatos ancestrales, como parte de los derechos humanos y de los derechos étnicos colectivos, en la exigencia de reparaciones históricas integrales y la construcción de una paz intercultural.
\end{abstract}

Palabras clave: Ecogenoetnocidio. Afrocolombianos. Derechos humanos. Defensa ambiental. Paz intercultural.

\section{ENVIRONMENTAL DEFENSE, HUMAN RIGHTS AND AFRO-COLOMBIAN ECOGENOETHNOCIDE}

\begin{abstract}
The article highlights the need to understand the neo-extractivist destruction that is occurring in the Colombian Pacific and in other parts of the planet, as an integral pattern, for it proposes the notion of ecogenoethnocide. Highlighting the environmental defense of Afro-Colombian communities, from the ancestral mandates, as part of human rights and collective ethnic rights, in the demand for comprehensive historical reparations and the construction of an intercultural peace.
\end{abstract}

Keywords: $\quad$ Ecogenoethnocide. Afro-Colombians. Human rights. Environmental defense. Intercultural peace.

\section{DEFESA AMBIENTAL, DIREITOS HUMANOS E ECOGENOETNOCÍDIO AFRO- COLAMBIANO}

\section{Resumo}

O artigo destaca a necessidade de entendermos a destruição neoextrativista que está ocorrendo no Pacífico colombiano e em outras partes do planeta, como um padrão integral, pois propõe a noção de ecogenoetnocídio. Destacando a defesa ambiental das comunidades afro-colombianas, dos mandatos ancestrais, como parte dos direitos humanos e direitos étnicos coletivos, na demanda por reparações históricas abrangentes e na construção de uma paz intercultural.

Palavras-chave: Ecogenoetnocídio. Afro-colombianos. Direitos Humanos. Defesa ambiental. Paz intercultural.

\footnotetext{
${ }^{1}$ Profesor PhD de la Universidad Andina Simón Bolívar. Quito. Área de Letras y estudios Culturales.
} 


\section{Introducción}

Hoy, en tiempos de la esperanza fijada por el postacuerdo de paz con la guerrilla de las FARC-EP, y los diálogos de paz con la guerrilla del Ejército de Liberación Nacional (ELN), que avanzan en medio de serios obstáculos e interrupciones, después de haber sido expulsado de Ecuador el equipo negociador, tras los confusos incidentes de secuestro y posterior asesinato de tres periodistas ecuatorianos, en la frontera norte con Colombia; provincia de Esmeraldas. Hechos que se atribuyeron a una disidencia de las FARC-EP, concentrando toda la atención y responsabilidad en un seudo guerrillero afrodescendiente, sin clara nacionalidad, apodado Guacho. Hoy, es indiscutible que a las afrocolombias rurales/urbanas, especialmente de la región del Pacífico, se les impuso una modernización tardía en plena marcha, por la vía de la guerra, el despojo y la destrucción de las culturas ancestrales, incluidos los grupos indígenas. Como lo ha señalado Arturo Escobar:

El desplazamiento forma parte integrante de la modernidad eurocéntrica y de la manifestación que ésta ha revestido después de la Segunda Guerra Mundial en Asia, África y América Latina, es decir: el desarrollo. Tanto la modernidad como el desarrollo son proyectos espaciales y culturales que exigen la conquista incesante de territorios y pueblos, así como su transformación ecológica y cultural en consonancia con un orden racional logocéntrico (ESCOBAR, 2004 p. 54).

Ello implica la eliminación de las diferencias económicas, ecológicas y culturales de las comunidades etnizadas, en la región del Pacifico, pero en general para los afrocolombianos, indígenas y campesinos del país; a través del despliegue de distintos dispositivos de homogenización por la vía de la eliminación física, la destrucción cultural y de los ecosistemas. Por lo tanto, ha significado la supresión total de las condiciones de vida y reproducción social en la normalidad que, históricamente, habían construido y diseñado estos grupos.

En este marco, el presente artículo destaca la manera cómo en la coyuntura que va desde finales de los años 80s, hasta la actualidad; pero con una clara exacerbación a partir de 1996, cuando se intensifican los destierros y despojos, a partir de la implementación de los megaproyectos legales con la expansión de la palma aceitera y la construcción de infraestructura de comunicación y expansión portuaria; confluyen, como parte de la misma matriz de recolonización, varias aristaso líneas de acción de la misma, aparentemente contradictorias, contrarias y hasta caóticas en su orden. Pero interconectadas y coherentes en la coyuntura, mostrando diferentes caras de esta modernización.

Una es la cara violenta, agresiva e ilegal con los grupos paramilitares, guerrillas, ejército nacional en su alianza paramilitar y narcotraficantes.La cara legal y promisoria con los proyectos ya mencionados, además de las intervenciones urbanas necesaria a la reproducción del capital; la cara amable y de salvación, con los proyectos estatales y de cooperación bilateral como Biopacífico y Plan Pacífico, las ONGs ambientalistas y, entre ellas, las tendencias conservacionistas de la naturaleza a través de reservas, cuidado de parques naturales y programas de educación ambiental con incidencia en el ámbito escolar, que se entroncaron bajo diferentes modalidades con la etnoeducación afrocolombiana, en tanto proyecto colectivo por una educación con identidad, pertinencia territorial y calidad desde la reconstrucción descolonizadora de la autoestima. Finalmente, la cara defensora, con las ONGs, agencias y demás institucionesque han promovido y promueven la educación en Derechos Humanos entre ellas la iglesia Católica y las Universidades.

Son en su conjunto faces a caras complementarias de dicha modernización, que se justifican mutuamente. Modelan, instauran e instituyen nuevos regímenes discursivos y nuevas prácticas sociales en el trabajo conjunto de imponer los cánones de esta modernidad periférica por varias vías. Debemos comprender, en consecuencia, que el tránsito de una socio-educación comunitaria rural relacional, fundamentada en el cuidado de la naturaleza, en relación con el ser humano y los seres intangibles; a una educación ambiental popular afrocomunitaria en el contexto rural y 
urbano,ha implicado una profunda modificación de las relaciones de estas comunidades con sus entornos; las cuales se ven cada vez más alejadas de ellos y, tal vez este esfuerzo implique en sí mismo una ausencia y una fragmentación cada vez mayor de las ligazones culturales y simbólicas; es decir, de la posibilidad de practicar sus conocimientos. Pero este tránsito, a su vez, se intersecta con la necesidad del aprendizaje acelerado de los derechos humanos, en condición de la continuidad de un destierro histórico, de genocidio, etnocidio y ecocidio.Lo que aquí se denomina de manera integrada un ecogenoetnocidio contra los afrodescendientes.

Teniendo en cuenta los constreñimientos y determinaciones características del caso colombiano y afropacífico, en el establecimiento de los diálogos de la diáspora africana en el sur del planeta, vale la pena traer a colación el siguiente planteamiento de Claudia Miranda:

Os fóruns sobre Educação para as Relações Etnicorraciais e sobre Educação em Direitos Humanos já buscam interseccionalidades com o tema da Justiça Ambiental e do direito ambiental não apenas nocontexto brasileiro. Tornou-se imperativo indagarmos sobre quais seriam os atalhos nos quais os povos da Diáspora Africana imprimem suas estratégias de luta pela vida para, assim existir/resistir na América Latina. Saber como esses grupos vem enfrentando o grande capital em espaços - rurais ou urbanos - onde o crime de Estado é a nova ordem estabelecida (MIRANDA, 2015, p. 226)

Para perfilar estos escenarios, primero presentamos algunas entradas conceptuales, al ecocidio, el genocidio, el etnocidio, la memoria y la interculturalidad. Luego nos adentramos en el panorama de la crisis humanitaria que viven los afrocolombianos y sus esfuerzos y propuestas por superar tal situación; por último, esgrime la construcción de una paz intercultural, a partir de la alianza afro-indígenas y con otros sectores sociales, realizadas en la gestión del acuerdo de paz.

\section{Ecogenoetnocidio}

El ecocidio se entiende como "el daño grave, la destrucción o perdida de ecosistemas de un territorio concreto, ya sea por mediación humana o por otras causas, a un grado tal que el disfrute pacifico de ese territorio por sus habitantes se vea severamente disminuido" (HIGGINS, 2010,p.15).

Sancionar el crimen de ecocidio busca invertir la lógica de lo sucedido hasta ahora, al favorecer a las mayorías. Los pueblos, grupos etnizados y regiones, frente al capital corporativo transnacional que ha tenido todas las ventajas para reproducir economías de enclave, neocolonialismos y neo-extractivismos. En el caso colombiano, conexo con el conflicto armado, se han presentado toda suerte de casos al respecto, tanto en términos legales, a través de concesiones, como ilegales, con empresas mineras que garantizan su seguridad y el despojo a través de ejércitos privados, ante todo paramilitares, además de los daños causados por las guerrillas con las voladuras de oleoductos, y las aspersiones con glifosato promovidas por el estado para la destrucción de las plantaciones de coca. Aspersiones que destruyeron el pan coger de los campesinos, indígenas y afrocolombianos, contaminando los cuerpos de agua y afectando la salud humana.

Al respecto, la Corte Constitucional reconoció las afectaciones ambientales y sociales en la cuenca del río Atrato, en el departamento del Chocó, al conferirle derechos al este río y solicitar reparación tanto para la cuenca como para sus pobladores, a través de la Sentencia T-622, de 2016 (COLOMBIA, 2016). Colocándose a tono con la tendencia cada vez más consolidada, de los derechos de la naturaleza o al medio ambiente como prefieren llamarle algunos. Lo sustantivo es que este fallo sienta precedente para que las comunidades, puedan exigir este derecho, de amplia violación antes y durante el conflicto armado interno.

De manera sucinta, se puede plantear que mientras el genocidio es la eliminación física de un grupo humano, en razón de una diferencia real o supuesta, el etnocidio es, en sí, la destrucción cultural, que puede ser paulatina en el tiempo o de forma acelerada e inmediata. Los dosfenómenos desde luego son inseparables en la experiencia de muchos grupos humanos, especialmente en el sur del planeta (JAULIN,1973). Como lo vemos, Colombia exhibe con abrumadores 
ejemplos,suficientes casos de genocidio, etnocidio y ecocidio; de ahí que para una comprensión holística de esta matriz necrófila, propongo llamarle ecogenoetnocidio.

Proponer este neologismo conceptual tiene el propósito de integrar, para la reflexión, fenómenos de destrucción, extinción de la vida y la cultura, agresión, despojo histórico y violación permanente y sistemática de derechos humanos y de la naturaleza, que, usualmente, se han presentado por separado en el discurso gubernamental, de las ciencias sociales y humanas; en el campo del derecho y de los organismos multilaterales de ayuda humanitaria. Integrar el ecocidio, el genocidio y el etnocidio, para comprenderlos de conjunto como un complejo patrón integral colonial, que se desenvuelve simultáneamente en estas múltiples esferas de la vida, resulta una necesidad heurística de reconstrucción holística.

Asumir como totalidad el desplazamiento interno, el refugio, los asesinatos selectivos, las masacres con su espectáculo de crueldad, el envenenamiento de los ríos, lagunas con mercurio en la minería del oro y la destrucción de las fuentes alimentarias y los tejidos sociales y culturales, concreta de manera evidente una matriz ecogenoetnocida, con efectos integrales de muerte y eliminación. Pero han operado y se han presentado como si se tratase de estrategias y acciones aisladas, velando la complementariedad de estos frentes de expulsión y destrucción cultural, que reducen a los otros bajo las formulas del mercado capitalista, a espectros desechables y folclóricos.

Al examinar fragmentariamente estos sucesos bajo las categorías canónicas que se están usando en el lenguaje colombiano, para reconstruir la historia del conflicto y proyectar la memoria y la historia para la reconciliación nacional, se corre el riesgo de reeditar la invisibilización histórica de la verdad, imponiendo un canon de verdad neocolonial desde las elites emblanquecidas, que en su fabricación de ésta, borran y silencian las protuberantes evidencias del destierro y el despojo histórico vivido por los grupos etnizados; esquivando, con ello, las responsabilidades estructurales y específicas. Es decir, corremos el riesgo de aceptar la instauración reproductiva del colonialismo cognitivo global en su edición nacional.

Reconociendo la utilidaddel lenguaje jurídico para exigir los derechos vulnerados y las reparaciones consecuentes, la ruta interpretativa que aquí se propone, busca mantener las conexiones complejas entre estos fenómenos y hechos criminales, para reconstruir su horizonte analítico desestabilizador de las categorías y representaciones que orientan el sentido común de la opinión pública a través de los medios de comunicación, en las políticas públicas y en la academia oficializada. Pretende impugnar, reinterpretar y proponer desde esta experiencia dolorosa, posibilidades de dignificación y humanización, a quienes se les ha arrebatado y destruido; en la larga noche de la colonialidad moderna.

\section{Memorias y post acuerdo de paz}

El tema de la memoria ha radicalizado el tono y los planteamientos en los países de este lado del planeta, sometidos a los embates neocoloniales, de manera muy especial, los flagelados por conflictos o guerras internas como es el caso de Colombia. Esta, además de considerarse una fuente histórica, cobra dimensiones políticas y epistémicas desde la mirada de los excluidos y empobrecidos en pugna o negociación con las élites. De ahí que se hable de políticas de la memoria y en algo más que un juego de palabras, de memorias políticas; para sacar a la luz, que ellos también han portado pensamiento político desde el cual han contribuido a los estado-nación y a la construcción de sus correspondientes sociedades. Revelando al tiempo la fabricación del olvido y el recuerdo, como un conjunto de decisiones inscritas en una relación dialéctica y de conflictos entre grupos sociales con posiciones y trayectorias históricas diferentes. El historiador africano Martin Kalulambi, al reflexionar la experiencia de la diáspora africana en la esclavización, fundamentado en Jean- Pierre Vernant, ha planteado al respecto:

La memoria historiográfica, que entiendo aquí como construcción y explicación critica del pasado, es un ejercicio de narración, un proceso de conocimiento siempre problemático e 
incompleto de lo que ya no es.[...] La memoria no es solamente huella sino recordar esos trazos: "su rol no es el de reconstituir el pasado abolido, de volver a presentarlo sino, atravesando las fronteras de un efímero hoy, volver al presente lo que vive escondido detrás de las apariencias". La memoria no es todo el pasado: La parte que continua viva" (KALULAMBI 2002, p. 454-457).

En esta discusión, el anclaje privilegiado como lugar de la memoria es la localidad; entendida esta como el lugar inmediato de producción y reproducción de la vida, de manera más amplia, incluso remite a la región como constructo sociocultural y simbólico, generalmente en contraposición a la globalización neoliberal-radical conservadora; que se acusa en abierta tendencia homogenizante y destructiva de los modos de vida que han garantizado la sostenibilidad de determinados ecosistemas, tal es el caso del Pacífico, el norte del Cauca y en general los valles interandino, la costa caribe, con presencia significativa de población afrodescendiente y las regiones de habitación de comunidades campesinas e indígenas.

De tal suerte, que la defensa del lugar y lo local tiene la impronta de relievar la diferencia, las otras opciones de construcción de proyectos de mundo. Lo que significa que se aboga, tal vez, por otro tipo de globalización; la globalización de las diferencias, algunos autores decoloniales como Walter Mignolo, Catherine Walsh y Agustín Lao-Montes, entre otros, agregan; de las diferencias coloniales.En consecuencia, las epistemologías y sabidurías locales y las prácticas comunitarias de lugar se resitúan interpelando al supuesto universal, hoy también podríamos hablar de lo universal hecho trizas.

Se pensaría más en términos de lo universalizado, como categoría histórica dinámica, evidenciando con ella, los siglos de la imposición colonial y la constitución de la colonialidad del poder, como matriz de la modernidad que invade todas las esferas de la vida, siendo fundamental la de producción de conocimiento experto para la toma de decisiones gubernamentales. Una pregunta inicial y suficientemente amplia, que nos permita sin embargo ganar contexto de problematización, incorporando el pensamiento de las víctimas es; ¿qué replanteamientos harían las memorias locales y regionales del destierro y del despojo histórico a la narrativa que se está oficializando, con el carácter de memoria nacional en el llamado post acuerdo en Colombia?

Estamos frente a nuevas opciones y condiciones para la emergencia de historias otras y, por lo tanto,verdades otras, para la expresión de nuevas narrativas en disputa por el derecho a existir; susceptibles de ser universalizadas en tanto experiencias comunes a otras latitudes que se pueden englobar en las nociones ya tratadas antes; que señalan crímenes contra la paz, la humanidad y responsabilidades morales y éticas. En adelante, ¿cuáles serían entonces las relaciones entre esas narrativas enfrentadas, teniendo en cuenta sus desigualdades entre las jerarquías del poder?, lo que implica en sí para los subordinados un posicionamiento de proyectos vitales. Proyectos históricamente menospreciados, que reclaman y proponen renovadas maneras de organización social, política y exigen al estado transformaciones, en que la pluralidad de memorias y opciones de vida tenga cabida, en tanto riqueza y no problema; como se ha considerado hasta ahora.

Enfaticemos. Pensar la historia, la memoria y por lo tanto el sentido de diversos conocimientos y experiencias culturales; éticas, políticas y estéticas, además de espirituales, de cara a las transformaciones del estado nacional, que favorezcan a los excluidos históricos, como lo muestra la coyuntura actual del post acuerdo en Colombia. Esto nos invita a repensar y replantear el problema de las memorias en relación con las identidades. Un indicador de ello es la exigencia por parte de Ministerio de Educación Nacional, de incorporar nuevamente, a partir de este año lectivo, la enseñanza de la historia en la educación básica y media, en estos momentos, después de casi una década de haber sido diluida en las ciencias sociales y expulsada del currículo nacional por impráctica.

Debemos preguntarnos, entonces, qué sucede en lo que sigue con las historias, las memorias y las identidades en el seno de las ciencias sociales y humanas y, en general, en el sistema educativo?¿Cómo deberían cambiar las memorias de gestión del estado-nación, con la emergencia 
de estas narrativas otras derivadas del conflicto armado en relación con la trata transatlántica?; ¿de qué manera deben vincularse la educación en derechos humanos con la educación ambiental en estas nuevas circunstancias que exigen transformaciones al sistema educativo en su conjunto?, $i$ en tal sentidoqué debería conocer un nuevo ciudadano, para accionar con justicia?.Las posibles respuestas tienden a confirmar lo planteado por Stuart Hall (2013), acerca de que los movimientos sociales crean momentos teóricos.

O lo que es lo mismo, las coyunturas políticas viabilizan concepciones que se movilizan luego en los discursos científicos, esclareciéndose los constreñimientos y la autonomía bastante relativa de la construcción social denominada ciencia y sus vínculos con el poder; pero por lo demás, las preguntas quedan abiertas al curso de las negociaciones y los escenarios. Esta especie de sismo epistémico y político desde la periferia, que amenaza y sobre todo interpela a los centros tradicionales de producción de conocimientos, nos hace conscientes de las posibilidades de nuevas geopolíticas del conocimiento, fundamentadas en experiencias históricas excluidas; la ciencia y la teoría política desde otros lugares, cuestionando un andamiaje conceptual de uso convencional.

\section{Sobre interculturalidad}

Con base en los elementos anteriores, se precisa la necesidad de habilitar un escenario de renovadas negociaciones y diálogos con relación a los estados nacionales y a los grupos hegemónicos sociales, políticos y económicos que han detentado el poder en estas sociedades.

Este escenario es el de la interculturalidad como proyecto ético, político, pedagógico, estético y espiritual, tendiente a transformar las condiciones de exclusión marginalidad y pobreza, es decir, que trata de concretar exigencias de justicia histórico-social, partiendo del cumplimiento de los derechosciudadanos fundamentales y, de manera más amplia, de los derechos humanos. Se trata de diálogos de culturas, de proyectos políticos y de concepciones del mundo para un nuevo pacto social, un renovado contrato donde el centro sea la justicia y la equidad entre los seres humanos, sus entornos y el planeta.

En esta perspectiva, la tarea es revertir las asimetrías sociales bajo una lógica de convivencia integral y holística, cuyo eje de articulación avanza en la emancipación de un pensamiento liberador para todos, cuestionando y proponiendo nuevos modelos de vida, aprovechando el acervo y los conocimientos de diversas comunidades ancestrales y tradicionales presentes en las naciones. El paradigma de la acumulación sin fin, bajo la idea de que los recursos del planeta aparentemente no tienen límite, no tiene asidero en este proyecto. De fondo, la interculturalidad propone opciones para nuevas lógicas civilizatorias, nuevas relaciones humanas, nuevas formas de producción y reproducción de la especie.

No es el viejo dialogo de saberes, en que si bien entraban en contactos memorias, historias, conocimientos de distinto orden y naturaleza, las jerarquías sociales seguían intactas; cuya consecuencia, generalmente, se evidencia en que el conocimiento experto, o en otras palabras, el saber eurocéntrico, termina incluyendo o asimilando el conocimiento de las culturas consideradas premodernas, exóticas o folklóricas. En esencia, es evidente que dicho diálogo no está regulado por un principio ético de respeto y responsabilidad; se dialoga, en últimas, para folklorizar al otro, para conocerlo como curiosidad clasificable dentro de la categorización del conocimiento oficial y válido, para continuar su proceso de colonización, homogenización y, finalmente, destrucción cultural.

En tal sentido, instando la óptica de la decolonialidad, la profesora Catherine Walsh ha planteado que podemos entender " la interculturalidad como proceso y proyecto social, político, ético e intelectual que asume la decolonialidad como estrategia, acción y meta"(WALSH, 2005, p. 25). El concepto de interculturalidad deviene central a la valoración y reconstrucción de pensamientos y experiencias desechadas por la modernidad y su doctrina de progreso y desarrollo, como opciones indispensables para nuevas oportunidades planetarias, nuevas formas de 
organización social y nuevas proyecciones globales. De ahí que algunos autores como Boaventura de Souza, se atrevan a plantear que desde el sur del planeta se está transformando la democracia, en nuevas maneras de abordar y diseñar el estado, a esto le ha llamado, "opciones de democracia intercultural" (De SOUZA, 2010, p 25.).

Por su parte, Jorge Viaña observa, en la interculturalidad planteada desde los movimientos sociales, especialmente del movimiento indígena, tal es el caso de Ecuador y Bolivia, una ruta ineludible en términos de oportunidades para redefinir de fondo el estado y la democracia, opina al respecto:

La matriz de cultura única moderna, basada en el Estado, el orden colonial de las sociedades latinoamericanas y las relaciones globales del capital, está incapacitada orgánicamente para "dialogar" y "respetar" y mucho menos construir "ciudadanía con igualdad". Lo paradójico es que los interculturalistas conservadores dan por sobrentendido que está cultura es la que puede y debe (por ser dominante y la base sobre la que se han modelado los Estados latinoamericanos) dirigir y articular el dialogo y la relación intercultural (VIAÑA, 2009, p. 6).

Para este autor, la interculturalidad así concebida se convierte en integracionismo sumiso, una inclusión subordinada; tras un constitucionalismo formal, bajo la retórica de la igualdad diferencial y un respecto abstracto, en el cual las asimetrías y desigualdades en la distribución de los bienes queda más o menos intacta, modelando, subsumiendo y sometiendo en consecuencia a lo diferente. Especialmente a los movimientos sociales y cualquier manifestación que se muestre como contradictoria de esta macrocultura del estado liberal y el capital. De esta manera, se exige al distinto, al otro, lo que esta monocultura no brinda: respeto y tolerancia. Disfrazando los etnocidios, los genocidios, los ecocidios, la arrogancia, las intolerancias y de conjunto la política de explotación y extermino de la diversidad cultural y de la naturaleza que despliegan las minorías detentoras de los privilegios, frente a las mayorías.

Después de este esbozo teórico, avanzamos a presentar la situación, el complejo contexto de crisis humanitaria de la región suroccidental a través de varias aristas que lo caracterizan, y permiten acercarse a una comprensión de sus dimensiones.

\section{Un contexto de despojos y vulneraciones crónicas}

Este aparte se propone presentar y discutir, de manera central, la difícil situación que atraviesan las comunidades afrocolombianas de la región suroccidental, en el contexto de crisis humanitaria que presenta el país, con los constreñimiento que tal situación implica, específicamente en el caso de la destrucción ecológica, del tejido social, económico y cultural; y en ello, los conocimientos ancestrales como articuladores de estas sociedades, asentadas especialmente en la región del Pacífico.

Entre 1996 y 2003, según datos del desaparecido Instituto Colombiano de Reforma Agraria, reemplazado por el INCODER, se habría titulado un total de 4.611.962,0447 hectáreas, a 127 consejos comunitarios, que agrupaban 51.679 familias, integradas por 275.996 personas. Es decir, un promedio de 5,3 personas por familia. Debe aclararse que la totalidad de este territorio no es cultivable, ni puede dedicarse a actividades productivas extensivas o intensivas y permanentes; debido a la fragilidad delos ecosistemas y a que varias zonas son de conservación de agua, madera, animales y diversas especies, por parte de las comunidades, de lo cual depende su permanencia en sus correspondientes territorios.

Entre 1996 y 2007, según información de la pastoral con base en los datos de INCODER, se titularon colectivamente 5.210.534,2628 hectáreas, asignadas a 63.312 familias, en la cuenca del Pacifico. A diciembre de 2017, después de la liquidación de INCODER, reemplazado por la Agencia Nacional de Tierras(ANT), se sabe que en todo el país existen 271 consejos comunitarios, de acuerdo con el observatorio de territorios étnicos y campesinos (OTEC) de la universidad 
Javeriana, sin embargo, no aparece el dato del número de consejos comunitarios que recibieron título en estos últimos años, en medio de la intensificación de la guerra con el Plan Colombia, presentando un represamiento la nueva ANT, de más de doscientas solicitudes de titulación, según versión pública de la funcionaria encargada.

No obstante, este significativo aumento de titulaciones colectivas en el periodo antes indicado, en medio de la guerra desatada contra la población de la región, revela una efectiva dinámica y liderazgo de las poblaciones y sus organizaciones, para hacer cumplir sus derechos y defender sus territorios colectivos; lo único que poseen a la postre estas comunidades, después de la esclavización y con la exclusión como fardo y secuela de ésta. De acuerdo con la visión del movimiento social, la aspiración es hacer titular 6.000.000 hectáreas sólo en el pacifico,propósito que aunque de manera parcial, haría justicia con su humanización y la ocupación histórica de estos territorios; lo cual se ha visto fuertemente impedido y paralizado mediante distintos mecanismos dilatorios del estado, las masacres y el destierro generado por los agentes de la guerra, con sus intereses económicos de explotación y saqueo.

\section{Destierro y crisis humanitaria afrocolombiana}

El multiculturalismo de estado y la multiculturalidad que promueve como una de las variantes discursivas de la interculturalidad conservadora, sirve de contexto a la peor crisis humanitaria que ha vivido la población afrocolombiana, por lo menos desde la segunda mitad del siglo XX. A la exclusión estructural que viven estas poblaciones, representada en los índices más bajos de calidad de vida del país, en conjunto con las comunidades indígenas; estando en todos indicadores por debajo de la media nacional - el $80 \%$ de la población sin posibilidades de cumplir la totalidad de necesidades básicas - la situación de destierro continuado, los coloca en una condición de mayor vulnerabilidad, agudizando su empobrecimiento, en la medida en que cercena sus posibilidades productivas y desarticula sus núcleos territoriales, sociales y culturales.

Debemos tener plena consciencia, de que nunca sabremos las dimensiones reales de este drama humanitario a través de las cifras, la diatriba por ellas entre las entidades del estado encargadas de la atención a las víctimas, las entidades internacionales en defensa de los derechos humanos y las cifras sustentadas por las organizaciones del movimiento social, así lo revelan. A las alarmantes diferencias en los volúmenes que representan los intereses en disputa y las dificultades del registro y la estrategia de subregistro de la problemática, implementada por estas entidades del estado, como una política de invisibilización y encubrimiento del ecocidio, el etnocidio y el genocidio, operado desde que avanzó en firme el proceso de titulación colectiva de los territorios, prevista por la ley 70 de 1993, se suman los emplazamientos y confinamientos generados por los grupos armados, que impiden la movilidad y restringen el acceso de víveres y alimentos a los territorios rurales y urbanos, tal es el caso de Buenaventura y Tumaco entre los más escandalosos. Es una especie de secuestro que nunca deja evidencias entre las violaciones de los derechos humanos.

En el marco de esta socioantropología de la mentira y el eufemismo; de hacer parecer lo que no es como si fuera, en que se han especializado grupos de funcionarios expertos, las cifras que se presentan sólo ilustran tenuemente una realidad, a la que la población colombiana parece haberse acostumbrado; normalizando su mirada sobre el horror y el crimen colectivo generalizado y las imágenes que produce en las ciudades capitales del país, el harapiento y mendigo personaje llamado con cierta indiferencia y desdén;desplazado y que, aquí, prefiero llamar desterrado, porque enuncia una condición histórica de larga duración; la diáspora afro, permanente en Colombia y el mundo. La crisis humanitaria perpetua, ya que ha sido un despojo histórico de su condición de humanidad.

Con base en datos de la Red de Solidaridad Social del 2001, se constata cómo la guerra focalizó sus intereses en el pacifico; entre los 37 municipios que expulsaron, en el año 2000, el 75\% de la población en el país, ocho municipios se encuentran en esta región, distribuidos los 
contingentes poblacionales de la siguiente manera: en el departamento del Chocó; Medio Atrato 3.289, Río Sucio 3.155, Quibdó 2792, El Carmen de Atrato 1.616, Juradó 1.287. En Antioquia; San Juan de Urabá 2.740 y Mutatá 1.596. En el Valle del Cauca; Buenaventura 3.800. Para un total del $16.30 \%$, lo cual no significa que todos sean afrocolombianos, pero sí que sus territorios son azotados por la violencia y el terror, como lenguaje emergente que se impuso codificando una nueva realidad de oprobios(ARBOLEDA, 2011).

$\mathrm{Al}$ momento de preguntarse en este registro por la etnia para el mismo año, se considera que de las 53.280 personas a las cuales se identificó, el 19\% son Afrocolombianos, es decir 10.100 y el $3 \%$ pertenece a la población indígena, o sea 1.542 (ALMARIO, 2004). Otro grupo de intelectuales, con base en la misma fuente oficial de la Red de Solidaridad Social, estima que para el segundo semestre del 2000, el porcentaje de afrocolombianos desplazados podría llegar a ser el $30 \%$ del total en Colombia, es decir 128.843 personas (MOSQUERA 2002, p. 39).La diferencia desde luego es muy amplia y diagrama la disputa por las cifras.

Del total de población expulsada de estos departamentos en el año 2000, año del despegue del Plan Colombia con el presidente Andrés Pastrana, según este registro, 38.877 personas, casi cerca de la tercera parte debió haberse dirigido fuera de la región, o sencillamente no se reportó en estos municipios como desplazadas, por diferentes razones, entre las más usuales, las trabas para en este procedimiento y las represalias y persecuciones de los paramilitares, aún en los contextos urbanos que se convirtieron en refugio.

Para el 2002, la cifra había crecido a 412.553 personas, $20 \%$ más que en el año anterior, más o menos 82.511 hogares desarraigados por la guerra; focalizándose, con mayor concentración, en el occidente del país, incluido el departamento del Chocó, con la trágica masacre de Bojayá, que expulsó el $68 \%$ de la población en este sólo evento. Toda la zona del litoral pacífico había entrado en disputa y se encontraba presa al tiempo de la intensificación del Plan Colombia, con la política de seguridad democrática del presidente Álvaro Uribe. Al respecto, CODHES (2003) calificó el 2002 como un año trágico para los grupos étnicos:

El 2002 representó para la población afrocolombiana el año más trágico en cuanto a desplazamiento, violencia, desintegración de comunidades, y pérdida de territorio y cultura. Al menos el 33\% del total de la población expulsada en Colombia, es decir, 83.650 personas, corresponden a este grupo étnico, sobre el cual se han ensañado los actores armados.La tasa de expulsión de las comunidades afrodescendientes es un $20 \%$ mayor que la del resto del país: mientras el nivel nacional registra 586 personas expulsadas por cada cien mil habitantes, la de comunidades afrocolombianas alcanza 736 por cada cien mil.En este orden de ideas, en 2002 el Chocó — con el $73.4 \%$ de su población compuesta por comunidades afrocolombianas-, es el primer departamento expulsor (4.498/100.000 habitantes) y receptor de población (3.678/100.000 habitantes). El Atrato, con una tasa de expulsión superior a la departamental (6.648/ 100.000 habitantes), es la segunda región del país con mayor tasa de expulsión, luego del Catatumbo (14.007/100.000 habitantes) (CODHES 2003, p. 3).

La seguridad democrática significó, para las comunidades afrocolombianas, la inseguridad total, la anulación de las mínimas garantías para el goce de sus derechos y la profundización de un ecogenoetnocidio sin precedentes, en la larga historia de la guerra en Colombia, la ruta de difusión y concreción de los derechos étnicos colectivos se vio obstaculizada, truncada y, en gran medida, suspendida en la práctica; ante las dimensiones de la destrucción y la hecatombe de las matanzas colectivas, como lo veremos adelante cuando abordemos las cifras de las masacres en estos territorios. Cercenaron las territorialidades cimentadas ancestralmente durante varios siglos.

En el Gobierno del presidente Álvaro Uribe (2002-2010), la Red de Solidaridad Social pasó a llamarse Agencia Presidencial de Acción Social, en su registro único de población desplazada (RUPD), encontramos que en el 2003, la población afrocolombiana representaba un 6\% del total nacional, mientras en el 2007 se había algo más que duplicado con un 14\%. Según el discutido censo del 2005, que minimizó al máximo el peso de esta población en el conjunto del país, cuya 
consecuencia inmediata fue producir un efecto de reducción de la catástrofe humanitaria en sus territorios y, la consecuente desactivación de las exigencias de calidad de vida, con base en su participación efectiva por su volumen. En otras palabras, se concretó un trabajo de minorización étnica, a través del juego de las estadísticas; en este inhumano y macabro juego, que recuerda las antiguas tácticas de los traficantes de africanos, para menguar la evidencia de la magnitud de su crimen, la población afrocolombiana representa 4.311.757, de ésta entre 1997 y el 2007, se habría expulsado de sus territorios 140.266 personas, es decir, un $10 \%$.

Distintas son las imágenes construidas por la Asociación de Afrocolombianos Desplazados (AFRODES), fundada en 1998, como respuesta a este embate sangriento. Para la misma década, 1997-2007, considera que 294.842 fueron expulsados de sus territorios colectivos, es decir el $21 \%$ de la población. En totales de población, 416.566 habitantes de los municipios con población afrocolombiana mayoritaria y 764.373 hab de los municipios de mayor concentración de población afrocolombiana fueron expulsados; lo cual incluye, desde luego, población afrocolombiana y no afrocolombiana, permitiendo revelar básicamente el impacto del desplazamiento en estas localidades. Pero, además, el documento analiza la extrema vulnerabilidad e imposibilidad para el acceso a empleo, educación, salud, vivienda y en general para los servicios públicos y el goce de sus derechos. Una situación de extrema precarización de la vida individual, familiar y comunitaria (AFRODES, 2008).

En el 2009, la cifra oficial de desplazados en Colombia era 3.073.010 personas, es decir; 695. 354 hogares a mayo, siendo este, por su volumen, el segundo desplazamiento interno más grande del mundo. Para organismos como el CODHES, la cifra podía superar los cuatro millones. Sin embargo, no se puede estimar aproximadamente cuántos son afrocolombianos y cualquier cálculo con base en las tendencias anteriores resulta exageradamente arriesgado. La falta de claridad en el registro de la variable étnica sigue siendo una limitante para acercarse en algo a una idea de la situación. Cómo lo reconoce un líder de los consejos comunitarios:

Hoy estamos todos como desplazados, porque víctimas, todos estamos dentro del conjunto de víctimas porque cuando se decía que si yo salí con diez niños cuando desplazado, ellos hacen parte de víctimas. Hoy sabemos que somos víctimas todos pero no sabemos si estamos inscritos como victimas todos (TUMACO, julio 26 de 2017).

En el Pacifico en particular, y en los territorios ancestrales de las comunidades afrocolombianas en general; norte del Cauca, Urabá y la costa caribe entre otros, se concentran los intereses de la modernidad capitalista legal e ilegal, en esta fase de acumulación voraz constituyeun torbellino de violaciones, alimentados por el combustible de la siembra de coca para la producción de cocaína; controlada por narcotraficantes, guerrillas y paramilitares. Una espiral destructiva de cualquier asomo de la autonomía reclamada por las comunidades, enseñoreada por la impunidad neocolonial, que los integra a su cruzada de desarrollo por la vía de la violencia y el destierro, en medio del envenenamiento de las aguas, los alimentos de pan coger y el aire, además del debilitamiento genético, aún sin valoración lo suficientemente clara, como antes lo hemos señalado $^{2}$, producidos por la aspersión, fumigación o concretamente la guerra química con glifosato, desatada contra esta población para acelerar el vaciamiento de los territorios y facilitar su explotación, so pretexto de erradicar las plantaciones de coca.

En este marco de desasosiego para los nativos, en el Pacifico se encumbran los símbolos infraestructurales del progreso, mientras las poblaciones huyen despavoridas: doble calzada CaliBuenaventura; reorganización urbana, nuevos centros comerciales etc. Con un cinismo

\footnotetext{
${ }^{2}$ Esta deber ser valorada en relación con los daños actuales causados a la salud de los habitantes, manifestados en problemas respiratorios, de piel, digestivos y demás, pero también en las proyecciones de daños futuros, por los impactos en las siguientes generaciones, cuando claramente se conoce de los efectos de este químico prohibido en el resto del mundo. Ademásdel daño ambiental integral irreparable.
} 
sorprendente, que aguza el interrogante: ¿Quiénes invierten en un pueblo en medio de la guerra?, la respuesta es obvia, sólo quienes la provocaron. Los que se presumen nuevos dueños y deben transformar el paisaje de acuerdo con su concepción estética y sus aspiraciones económicas; se trata de arrancar una cultura, un modo de vida e imponer otro, el que dictamina la globalización, el estándar del confort. Con plena consciencia un profesor de bachillerato en la zona rural de Tumaco nos explica:

\begin{abstract}
Yo siempre he dicho que la razón del desplazamiento y de las grandes masacres es para que nosotros abandonemos nuestro territorio, porque hoy la lucha del Estado y de las grandes naciones es por el territorio. No hay otra. Yo siempre he dicho que toda esta lucha es por el territorio; aquí no es que porque hay cierto grupo o porque allá hay coca. No. Es porque necesitan el territorio y nosotros somos como un obstáculo en el territorio. Y ha pasado no solo aquí, nosotros que hemos recorrido a nivel mundial, lo que hemos sufrido nosotros se ve en otros países, porque como tenemos toda la materia prima entonces hoy como nosotros estamos metidos allí, entonces ellos quieren sacarnos de allí para ellos ahora sí sacarle el jugo a lo que ellos quieren hacer. Hacia allá es que va encaminado todo. Y toda persona que se oponga a resistir en ese territorio es masacrada. Yo siempre he dicho que la fumigación es que buscan una forma de matar a la gente para que no se vea el impacto de que están dando plomo y que la gente abandone el territorio. La minería en alta escala nos contamina el agua, usted sin agua no puede vivir, entonces tiene que salir a mendigar agua acá, a engordar la miseria en las grandes ciudades como están los desplazados acá y deja la riqueza para que ellos la exploten. Allá estamos pensando y estamos diciendo siempre que todo esto que está pasando es por el territorio (TUMACO, julio 25 de 2017).
\end{abstract}

La crítica situación del eje Tumaco-Buenaventura se explica por la concentración de los intereses económicos en este último, el principal puerto del país, con varios megaproyectos que van desde la ampliación de la oferta portuaria, pasando por la pesca industrial y aprovechamiento hidroeléctrico, hasta la explotación minera y agropecuaria de los territorios en su mayoría ya titulados a las comunidades afrocolombianas. De igual manera se puede situar el caso de Tumaco, con la presión por la expansión de los cultivos de palma aceitera; y los municipios del Cauca, acosados por la minería ilegal del oro; siendo el caso emblemático el corregimiento de la Toma, en el municipio de Suarez; una enorme mina a cielo abierto y la amenaza de desaparición de su poblamiento afrodescendiente presente desde el periodo colonial ${ }^{3}$.

Durante toda la década, el corredor pacifico mantuvo el mayor número de destierros en el promedio nacional, convergiendo la degradación de la guerra con todo tipo de violaciones a los derechos de los grupos étnicos, así lo registro CODHES, en sus informes trimestrales y especiales, hasta llegar al 2015; en que con motivo de los diálogos de paz con la guerrilla de las FARC-EP, disminuyeron sensiblemente los eventos de destierros masivos y masacres; el pacifico continúo presentando la crisis humanitaria más visible, debido a que parte de los diálogos de paz se dieron en medio del fuego y las hostilidades de ambos ejércitos; manteniendo también el desborde del conflicto hacia las fronteras con Ecuador y Panamá, tendencia que permanece hasta el presente.

Frente a esta situación, el auto 005/09 de la Corte Constitucional, llamó la atención sobre esta crisis humanitaria, la negación de garantías y, en consecuencia, la violación sistemática de los derechos humanos y del derecho internacional humanitario. Calificándola de desproporcionada, desmedida en relación con otras regiones y poblaciones del país, en razón de la discriminación histórica como causa de las violencias estructurales que se habían vivido y se estaban viviendo; ordenando, por lo tanto, al estado la puesta en marcha de un enfoque étnico diferencial para estas comunidades. Lo cual incidió de cierta manera en el giro discursivo, sobre todo en algunas ONGs

\footnotetext{
${ }^{3}$ De este corregimiento es la líder Afrocolombiana Francia Elena Márquez, quien después de muchos años de lucha en defensa de los derechos humanos y el medio ambiente en su municipio, pero en general en el norte del Cauca, en contra de la minería del oro a cielo abierto, en abril del 2018, le fue otorgado el premio medioambiental Goldman. Debe destacarse la labor educativa comunitaria desarrollada por ella y su grupo de trabajo, que articula de manera dinámica la educación ambiental como parte de la exigibilidad y el goce de los derechos humanos.
} 
nacionales e internacionales, y cierto sector de la academia critica, que de conjunto prestaron mayor atención a la relación existente entre exclusión histórica, discriminación racial y las violencias coyunturales del conflicto armado interno; sobre todo tratándose de derechos consuetudinarios reconocidos constitucionalmente,como acervo colectivo de la diferencia de este grupo afrodescendiente. Ello se puede apreciar en el análisis de CODHES.

En el informe correspondiente al año 2012 "La Crisis Humanitaria en Colombia Persiste. El Pacífico en disputa.", CODHES advirtió sobre la intensificación del conflicto armado en esta región del país, situación que ha persistido y se ha agudizado en los últimos días. Este escalamiento del conflicto armado va en contravía de los anhelos de paz de los colombianos y pone en una situación de desprotección a la población que habita en esta región del país.

Los ataques recientes de los que han sido víctimas estas comunidades incluyen voladura de torres de energía, atentados indiscriminados con artefactos explosivos, bombardeos, miles de desplazamientos forzados, confinamiento, asesinatos selectivos, amenazas colectivas e individuales, entre otras acciones que se constituyen en violaciones a los derechos humanos y las libertades fundamentales de los afrodescendientes y demás habitantes de esta región, en particular, en ciudades como Tumaco, Barbacoas, Magüi Payán (Nariño), Guapi, López de Micay (Cauca), Buenaventura (Valle del Cauca), al igual que en el departamento de Chocó. Desde 2010 hasta 2014 produjeron más de 350 eventos de desplazamientos masivos, afectando a por lo menos a 70.000 personas, esto teniendo en cuenta que el desplazamiento masivo representa cerca del $14 \%$ del total de personas desplazadas da cuenta de la concentración de los impactos del conflicto en esta zona del país (CODHES 2015, p. 1-2, énfasis nuestras).

En este periodo, el 21\% de las personas reportadas en el Registro Único de Victimas (RUV), sistema oficial del estado, provienen de estos departamentos de mayoría afrodescendientes, con el mayor número de territorios colectivos titulados. Para el caso del litoral suroccidente, entre mayo 11 del 2000 y mayo 28 de 2013, según datos registrados oficialmente por el Centro de Memoria Histórica, Paz y Reconciliación, a través de su proyecto rutas del conflicto, se habrían presentado 44 masacres, el $90 \%$ aproximadamente perpetradas por los paramilitares denominados autodefensas unidas de Colombia, las restantes fueron ejecutadas por las FARC-EP, las bandas criminales (BACRIM) derivas de la desmovilización paramilitar, a partir del 2004 y grupos no identificados, algunos con uniformes del ejército colombiano, según versiones de las víctimas.

La mayor masacre se presentó en el corregimiento de Llorente, municipio de Tumaco, el 30 de junio de 2004, en la cual fueron asesinadas veinte personas, la sigue en cantidad de muertes lo sucedido el 11 de mayo del 2000, en el corregimiento de Zabaletas, municipio de Buenaventura, con trece asesinatos, registrándose el menor número en variados eventos al menos seis, con cuatro asesinatos, para un total de 273 personas masacradas, ateniéndonos a las cifras oficiales.Más de medio millón de desplazados se reportan entre 1999y 2013 en la región.

El informe conjunto del Centro de Monitoreo de Desplazamiento interno (IDMC) y el Consejo Noruego para Refugiados (NRC), publicado en mayo del 2017, consideró que a diciembre 31 de 2016, Colombia ocupaba el primer lugar del mundo en número de desplazados internos con 7,2 millones, seguido de Siria, 6,3 millones; Sudan 3,3 millones e Iraq con 3 millones. En 2015, Colombia había ocupado el segundo puesto, con 6,2 millones, por debajo de Siria con 6,6 millones. Este aumento muestra mejores niveles de conteo y consolidación de la información, al tiempo que la continuación de la guerra con fuerte intensificación en zonas de frontera como la que estamos estudiando.

Para CODHES (2016),solamente los afrocolombianos desplazados pueden ascender al 22\% del total de desplazados del país, esto es más de un millón y medio de personas. Lo que sugiere que al agregar las masacres, delitos sexuales, daños territoriales y demás violaciones, tal vez podemos estar ante uno de los más grandes, sino el mayor, genocidio, etnocidio y ecocidio de las Américas contra los afrodescendientes en este periodo. No tenemos datos similares en el continente, pero dejémoslo planteado como sospecha por que no corresponde a este articulo tal comparación. 


\section{Entre mandatos y derechos}

Mientras asistimos al drama del desmembramiento social, cultural y a la limpieza étnicoracial, las mismas transnacionales artífices de esta destrucción, a través de sus fundaciones y de terceros nacionales, vienen promoviendo la formación de una capa de líderes jóvenes, en el pacifico y en general en los territorios afrocolombianos, en que tienen concentrados sus intereses; bajo la impronta individualista del pomposo emprendimiento neoliberal. Este es un segmento de la cara o faceta legal y promisoria de la modernización y su doctrina de desarrollo.

Los nuevos emprendedores, en diferentes campos, avanzan en la legitimación del destierro histórico, descalificando la búsqueda y construcción de alternativas basadas en sus derechos colectivos ancestrales; oficializando, en consecuencia, la mentalidad del sálvese quien pueda. Este mezquino liderazgo, viene cumpliendo la función de acelerar la expoliación, usurpando lugares de representación y decisión, mientras promueve las virtudes de la vida urbana, fuera de los territorios colectivos. Puntualicemos, aquí, que mientras se promueve la expulsión territorial, el despojo legal de la cultura y la dignidad, avanzando aceleradamente en la extinción de este pueblo, las multinacionales se apoderan de sus bienes, mientras el pueblo afrocolombianos y sus comunidades se agrupan en las ciudades de refugio esgrimiendo los derechos humanos y el derecho internacional humanitario, que han tenido que apropiar también de prisa, en la situación de calamidad comunitaria.

Con ello se excluye y, finalmente, se borra la posibilidad de ejercer sus principios y mandatos ancestrales, ligados a sus territorios y soportes de los conocimientos y las prácticas sociales. Como lo expresaría el maestro Juan García (2017): estos mandatos y principios han sido sembrados, cultivados y resembrados incesantemente en el territorio por los ancestros, en este sentido serían anteriores a la gramática de los derechos humanos con sus sesgo individual moderno; y desde estos principios y mandatos en las últimas décadas de negociaciones con los estados nacionales, y con la comunidad internacional, se han construido y defendido los derechos colectivos $\mathrm{y}$ ancestrales.

Es claro, entonces, que como sujetos colectivos y comunitarios etnizados, los afrocolombianos y en general los afrodescendientes ven la garantía real de la vida en el planeta, en el enraizamiento de estos principios y mandatos, anteriores a la modernidad; que van más allá de ella y del capitalismo, en la medida en que estos son la conexión compleja, relacional y holística entre mundos que conviven en los planos tangibles e intangibles; entre los humanos y los no humanos, entre los vivos y los muertos. Son en sí, una ontología que soporta un entramado de prácticas, conocimientos y significaciones bioecocéntricas colectivas. Es el cuidado de la vida planetaria desde abajo.

Si bien la cara defensora con la institucionalidad de los derechos humanos, como la Comisión Interamericana de Derechos Humanos (CIDH), con sus medidas cautelares, producto de las denuncias y alarmas producida por las comunidades o la defensoría del pueblo, así mismo Ongs, entidades ligadas a la iglesia católica, como el Servicio Jesuita de Refugiados (SJR) y la academia, entre otras que producen informes especializados y estudios; cumplen la función de oponerse a la violencia y a esta violación sistemática y por ello su trabajo no es nada despreciable y por el contrario se convierte en un frente fundamental defensa, de registro, memoria y reflexión para la exigibilidad frente al estado; su eficacia en las actuales circunstancias es bastante limitada, teniendo un efecto básicamente retórico. No obstante, debe resaltarse el ejercicio y la articulación de una acción contra-hegemónica desde los derechos humanos, que al menos ha servido para señalar la responsabilidad del estado por acción u omisión.

Las caras o faces de que hemos hecho mención, en su conjunto están contribuyendo a la construcción de un sujeto individual modernizado tardíamente, desarticulando sus pertenencia y 
sentidos colectivos y comunitarios étnico ancestrales, como parte de la modernización de los territorios bajo la matriz homogenizadora blanco-mestiza, con una institucionalidad jurídica y política que destruye los sentidos propios de organización de la vida social y cultural. En otras palabras, desde diferentes frentes se está fabricando un nuevo sujeto, una nueva subjetividad que coloca fin a estas construcciones socio-culturales y económicas, ha estos diseños de la vida, instalando el logocentrismo y las lógicas capitalistas.

Frente a tantos rostros de esta destrucción, que se muestran contradictorios, confundiendo con frecuencia a la población, las propuestas y respuestas de las comunidades a través de sus organizaciones y los consejos comunitarios han sido frecuentes, desde marchas, mítines, paros cívicos, expulsión de varias localidades a los paramilitares etc; además de declaratoriasde espacios humanitarios, tal es el caso Espacio HumanitarioUrbano, ubicado en el barrio de los nayeros, en Buenaventura, conformado por 302 familias; muchas de las cuales proceden de la masacre del rio Naya, perpetrada por grupos paramilitares entre el 10 y el 13 de abril de 2001. Este primer Espacio Humanitario Urbano fue creado en abril de 2014, liderado por jóvenes de la comunidad, defensores de derechos humanos, acompañados por un amplio grupo de organizaciones internacionales de derechos humanos, lo cual hizo posible que la Comisión Interamericana de Derechos Humanos (CIDH), dictara la medida cautelar 152-14, de septiembre de 2014. No obstante el hostigamiento y las amenazas contra los líderes y la población continúan.

En su conjunto, estas estrategias propuestas apuntan a la construcción de la paz y a la exigencia de reparaciones colectivas e individuales e indemnizaciones por los daños causados; sin embargo, este camino ha sido ampliamente accidentado y tortuoso; repleto de dilaciones e incumplimientos de la legislación existente.

\section{La utopía de una paz intercultural}

A la luz de estas propuestas y de las experiencias concretas que vienen desarrollando los afrocolombianos en el pacifico y en el país, al pensar las posibilidades e imposibilidades reales de la interculturalidad, como proyecto dialógico, en la óptica de redefinición del estado nacional colombiano, más aún en el actual proceso de paz; que haga posible una redistribución del poder político, económico y garantice el respeto de los acervos simbólicos y las prácticas socioculturales, es decir, las concepciones de la vida y el mundo que portan estas comunidades, expresadas en sus conocimientos conectados armónicamente a sus ecosistemas, al igual que otros grupos culturales, en tanto riquezas diversas constitutivas del país y la nacionalidad.

Debemos esgrimir, enfáticamente, que se trata de una matriz de múltiples aristas y por ello holística e integral, que se propone desde Sur América y especialmente los países andinos, como posibilidad de confluencia de proyectos y horizontes sociales, culturales, económicos y ecológicos que propenden por aportar renovados cauces y experiencias, que permitan valorar conocimientos y pensamientos hasta ahora no tenidos en cuenta por el modelo de civilización imperante, para la construcción de utopías posibles.

En este sentido la interculturalidad no existe, y están en marcha varias experiencias en el rediseño del estado-nación y de las sociedades, bajo racionalidades, sensibilidades, espiritualidades, sabidurías y epistemologías descolonizadoras de la existencia vital planetaria. Algunos casos son los de Ecuador y Bolivia, con todas las dificultades y diferencias entre sí que ello entraña. En el caso de Colombia, el asunto es aún mucho más complejo e intrincado. Estamos, entonces, ante una oportunidad en construcción, frente al desastre que muestra la cultura civilizadora, colonizadora capitalista; se trata de una amplia propuesta de salida del proyecto de muerte acelerada de la diversidad planetaria; es asunto de vida o muerte, para el cambio de matrices civilizatorias distintas, ahí radica su posibilidad mayor, en nuevas maneras de enfrentar las relaciones sociales, políticas, la experiencia estética y demás dimensiones; habiendo incorporado la diferencia y la pluralidad, como 
un principio ético-político indispensable para la pervivencia como especie, en mejores condiciones que las actuales.

En el caso central que nos ocupa, son notorias las grandes imposibilidades para concretar un dialogo respetuoso y tolerante con el estado y sus elites blanco-mestizas incrustadas, pero además con la mayoría de los sectores económicos poderosos. Dialogo que tienda a la equidad y a la transformación concreta de las condiciones de exclusión y subalternización histórico estructural socio-racializada. Los afrocolombianos, indígenas, los movimientos sociales, organizaciones y liderazgo en general, siguen ensayando estrategias y mecanismos para ir allanando los caminos en el mediano y largo plazo. ¿Qué elementos se podrán encontrar en común en las agendas de estos diversos intereses entre Estado, empresarios y comunidades?, temas como las amenazas ambientales comunes y/o los desastres de hecho, harán movilizar los intereses económicos y de política pública estatal a tono con las agendas, demandas y políticas de las comunidades?. La bitácora es bastante amplia y, hasta cierto punto, incierta para las comunidades, pero parte de reconocer la potencialidad y capacidad de realización colectiva en ejercicio de su autonomía en un eje, al tiempo que en otro eje de carácter jurídico, se da la batalla por el cumplimiento de las reparaciones integrales, acorde con la legislación que asiste a estas comunidades.

Esta bifurcación estratégica transparenta que el ecogenoetnocidio está representando un proceso de ciudadanización e inclusión por la vía de la violencia extrema; una inclusión forzada, a las políticas del mercado y el estado capitalista neoliberal. Es uno de los precios de la modernización subalternizada, en que la ciudadanía plena está negada, tras el despojo y la vulneración sistemática y continuada de sus derechos.

Pero también, en este contexto, la etnofagia tiene cartas en el asunto,construyendo una capa social medía, generalmente jóvenes del mismo grupo étnico, con mayores niveles de educación formal que el promedio, constituyendo una mediación para traducir los nuevos lenguajes y prácticas que emergen con todo el paquete de la ayuda humanitaria,derechos humanos y del derecho internacional humanitario; fraguando uno de los canales de esta interculturalidad, que sirve al tiempo, de mecanismo de inclusión diferencial homogenizante en la desgarradora ciudadanización; en su dimensión abstracta y concreta, que se percibe en la nueva experiencia, a través de los cuerpos en los nuevos lugares, las nuevas situaciones y experiencias a que están expuestos. En medio de esta complejidad se debe tramitar la interculturalidad desde las memorias pasadas y presentes en relación con las elites y el estado colombiano.

Como otra arista de lo anterior, este proceso de destrucción ecogenoetnocida coloca a prueba las suficiencias íntimas (ARBOLEDA, 2011), activando las resistencias y las re-existencias plurales hacia la construcción e institucionalización de un renovado consenso y consentimiento activo, que tiende a la articulación de una hegemonía popular étnica, a través de ingentes esfuerzos de comprensión mutua; lo cual resulta evidente en logros como el capítulo étnico, incluido en el acuerdo de paz con las FARC-EP, elaborado y tramitado en conjunto con el movimiento indígena.

Este bloque étnico popular heterogéneo, con su movilización desde abajo, tiene en común la defensa integral de la vida individual y colectiva, sobre la base de la defensa de los territorios colectivos y el derecho a la diferencia igualitaria; de esta manera, entronca los derechos ambientales como parte de los derechos humanos y de los derechos colectivos. Son la base de la etnoeducación, desde la siembra de los principios y mandatos ancestrales, que devienen en educación y defensa de los ecosistemas y territorios.

Este punto de partida es un bien común, que redefine lo público y su agenda estrictamente neoliberal en Colombia y por eso configura un verdadera pugna por la autonomía y la autodeterminación, expresando una tensión, una fisura en la concepción y organización del estado nacional. Fisura que, en un ámbito, habilita las posibilidades de dialogo intercultural e interhistórico hacía negociaciones justas, pero al tiempo, en su exigencia, agudiza los niveles de violencia, de eliminación física, de destrucción, ante el monoculturalismo y el totalitarismo de las elites; por ejemplo ante la exigencia de consulta previa, consentida e informada. 
Podemos observar, entonces, que frente a la doble estrategia político jurídicacomunitaria, también la estrategia del poder es bifurcada; al tiempo que presenta la seducción y cooptación etnofagica en la ruta de la negociación pacifica, opera el genocidio y el ecocidio; la matriz colonial del poder en su integralidad. Esto diagrama el escenario dialéctico y la tensión inestable y permanente que dinamiza las tendencias para la construcción y reconstrucción de lo público y el estado-nación.

De sus complejas articulaciones, combinaciones y mezclas en el posicionamiento de los proyectos y subjetividades en disputa, pueden resultar diseños inesperados, o en el peor de los escenarios, para los excluidos históricos, su borramiento; no solo del escenario político, sino de la existencia concreta, según lo venimos sustentando. Como ha sucedido a varios grupos indígenas en el continente. En cualquier caso, la lucha por la memoria y la historia es crucial y determinante, destacando esas memorias históricas de dignificación y lucha que encarnan y no ocultan las realizaciones interculturales desde abajo, claves a las consciencias y a las agendas de transformación para justicia social y la equidad planetaria y en el país.

Estaríamos hablando, entonces, como posibilidad, de la fecundación vía la continuidad de las relaciones, donde ya se encuentran establecidas, con miras a construir alianzas y comprensiones convivenciales duraderas, como lo hemos constatado en la experiencia afro-indígena en el Pacifico y en otras regiones. Es la emergencia de una interculturalidad desde abajo, contra-hegemónica; interculturalidad insurgente y resistente, en principio interculturalidad subalternizada, que a las elites en el poder, les asigne y patentice su sentido real de minorías privilegiadas. Esta es una posibilidad real de democracia sustantiva, incluyente y directa desde las bases.

Por lo tanto, no es una experiencia realmente nueva, y serviría para modificar la correlación de las agendas en los escenarios de negociación de la paz en el país, y el establecimiento de un nuevo pacto social. Pero deben caber y participar los otros grupos, que claman por soberanía y autonomía alimentaria y alimentos de calidad, por buen aire, agua y educación pertinente con las condiciones ecosistémicas en las regiones y acorde con las necesidades culturales y económicas reales del país; como lo plantean los postulados y las experiencias de la educación propia y la etnoeducación, o sea, recuperar y restaurar lo arrebatado en la guerra.

La otra arista de esta ruta podría estar en los sectores de la comunidad internacional, que han mostrado coincidencia en la idiosincrasia, en visión ideológica y programática; un ejemplo de esto son los ambientalistas que entienden la dimensión social como parte integrante de la defensa del planeta; pero también algunos sectores de la iglesia católica, que de algún modo se expresa en la pastoral afroamericana, además de algunas iglesias protestantes, entre otros grupos con los cuales se han articulado campañas coyunturales.

Entendiendo la simultaneidad de acciones que desarrolla el movimiento social afrocolombiano y las organizaciones que lo integran, creo que avanzar en la concreción decida de esta interculturalidad desde abajo, puede habilitar inmensas ventajas para todos los sujetos que entren en la alianza, en la confrontación dialógica y tensa con el estado y las minorías que están imponiendo el modelo de dictamen único en detrimento de la polifonía que nos caracteriza como nación y como regiones. Contribuyendo desde sus identidades, sus memorias, sus historias que entrañan sus comprobadas filosofías de la existencia para el buen vivir y el bien colectivo, en oposición y como alternativa al individualismo a ultranza, que llena sus arcas engullendo y destruyendo las posibilidades de recrear y reinventar incesantemente la experiencia vital, posibilidad que se alberga en la pluralidad esencial que somos.

Lo anterior es la búsqueda de la paz intercultural, que supera la imposición de la paz blanca, esto es, más allá del predicamento formal de país, nación y sociedad pluriétnico y multicultural, el cual se sigue amplificando en las propuestas de reparación (CNMH 2015, p. 450). Ello es un requisito imprescindible para la sostenibilidad y durabilidad del nuevo acuerdo social en ciernes, es decir, para una efectiva reconciliación entre los colombianos. Enfaticemos, es indispensable e 
imperativa la construcción e institucionalización de una paz desde las múltiples voces, memorias, conocimientos y experiencias en la construcción del país; de una paz intercultural.

\section{Referencias}

ASOCIACIÓN DE AFROCOLOMBIANOS DESPLAZADOS (AFRODES). Proceso de Comunidades Negras (PCN), Conferencia Nacional de Organizaciones Afrocolombianas (CNOA) y otros. Política pública con enfoque diferencial para población afrocolombiana en situaciones de desplazamiento forzado o confinamiento. Documento marco. Bogotá. Julio de 2008, (inédito).

ALMARIO, O. Dinámicas y consecuencias del conflicto armado colombiano en el Pacifico: limpieza étnica y desterritorialización de afrocolombianos e indígenas y `multiculturalismo’ de Estado e indolencia nacional. En RESTREPO, E.; ROJAS, A. Editores. Conflictos e (in) visibilidad. Retos en los estudios de la gente negra en Colombia. Popayán: Universidad del Cauca, 2004. p. 73-20.

ARBOLEDA Q. S.Destierro afrocolombiano: la interculturalidad imposibilitada. En BONDIA, G.;MUÑOZ, D.; MUÑOZ, M. R. (Orgs.).Los movimientos sociales en la construcción del Estado y la nación intercultural. Barcelona: Editorial Huygens, 2011. p. 159-194.

CENTRO NACIONAL DE MEMORIA HISTÓRICA (CNMH). Buenaventura: Un puerto sin comunidad. Bogotá: Imprenta Nacional de Colombia, 2015.

CONSULTORIA PARA LOS DERECHOS HUMANOS Y EL DESPLAZAMIENTO (CODHES). No 44. Bogotá: CODHES, 2003.

CONSULTORIA PARA LOS DERECHOS HUMANOS Y EL DESPLAZAMIENTO (CODHES). No 84 . Bogotá: CODHES, 2015.

CONSULTORIA PARA LOS DERECHOS HUMANOS Y EL DESPLAZAMIENTO (CODHES). Guía para la reparación colectiva de los pueblos y comunidades afrodescendientes en el marco del Decreto Ley 4635 de 2011. Bogotá: CODHES, 2016.

DERRAME de petróleo en Tumaco es el peor desastre ambiental en 10 años: Gobierno.El Espectador, Bogotá, 25 Jun. 2015. Disponible en: <https://www.elespectador.com/noticias/nacional/extreman-medidascontener-derrame-de-petróleo-tumaco-articulo-568409>. Acceso en: 17/8/17.

ESCOBAR, A.Desplazamiento, desarrollo y modernidad en el Pacifico colombiano.En RESTREPO, E.; ROJAS, A. Editores. Conflictos e (in) visibilidad. Retos en los estudios de la gente negra en Colombia. Popayán: Universidad del Cauca, 2004. p. 53-72.

Juan GARCIA, J.: WALSH, C.Pensar sembrando/sembrar pensando con el abuelo Zenón. Quito: Universidad Andina Simón Bolívar- Ediciones Abya Yala. 2017.

HALL, S.Sin garantías. Trayectorias y problemáticas en estudios culturales. Quito: Universidad Andina Simón Bolívar, 2013.

HIGGINS, P.Erradicating Ecocide: laws and governence to prevent the destruction of our planet. London: Shepheard-Walwyn Publishers, 2010.

JAULIN, R. La Paz Blanca: Introducción Al Etnocidio. Buenos Aires: Tiempo contemporáneo, 1973.

KALULAMBI, M. Memoria de la esclavitud y polémica sobre las reparaciones. En MOSQUERA, C.;PARDO, M.; HOFFMANN, O. Editores. Afrodescendientes en las Américas. Trayectorias sociales e 
identitarias. 150 años de la abolición de la esclavitud en Colombia.Bogotá: Universidad Nacional de Colombia, 2000.p.453-476

MIRANDA, C. Educação Ambiental, educação das relações etnicorraciais e as confluências no campo dos direitos humanos: dos quilombos às favelas. EmLOUREIRO, C. F. B. et al. (Orgs.). Pensamento Ambientalista numa sociedade em crise.Macaé: NUPEM/UFRJ, 2015. p. 225-248

MOSQUERA, C.;PARDO, M.; HOFFMANN, O.Las trayectorias sociales e identitarias de los afrodescendientes. En MOSQUERA, C.;PARDO, M.; HOFFMANN, O. Editores. Afrodescendientes en las Américas. Trayectorias sociales e identitarias. 150 años de la abolición de la esclavitud en Colombia. Bogotá: Universidad Nacional de Colombia, 2000.p.13-42

REPÚBLICA DE COLOMBIA. CORTE CONSTITUCIONAL. Auto 005, 26, enero, 2009. Protección de derechos fundamentales de la población afrodescendiente víctima del desplazamiento forzado en el marco de la superación del estado de cosas inconstitucional declarado en la sentencia T-025/04. Bogotá: CORTE CONSTITUCIONAL, 2009.

REPÚBLICA DE COLOMBIA. CORTE CONSTITUCIONAL. Sentencia T-622, 10, noviembre,de 2016. Acción de tutela interpuesta por el Centro de Estudios para la Justicia Social "Tierra digna".Bogotá: CORTE CONSTITUCIONAL, 2016.

REPÚBLICA DE COLOMBIA. MINISTERIO DEL INTERIOR.Decreto Ley $N^{\circ} 4635$, 9, diciembre,de 2011. Por el cual se dictan medidas de asistencia, atención, reparación integral y de restitución de tierras a las víctimas pertenecientes a comunidades negras, afrocolombianas, raizales y palenqueras.Bogotá: MINISTERIO DEL INTERIOR, 2011.

De SOUZA, B. Refundación del Estado en América Latina: perspectivas desde una epistemología del Sur. Bogotá: Uniandes y Siglo del Hombre.2010

VIAÑA, J. La interculturalidad como herramienta de emancipación. Hacia una redefinición de la interculturalidad y de sus usos estatales. La Paz: editorial "campo Iris". 2009.

WALSH, C. Introducción. En WALSH, C. Editora. Pensamiento crítico y matriz (de)colonial: reflexiones latinoaricanas. Quito: Universidad Andina Simón Bolívar-Ediciones Abya-Yala, 2005.p. 13-35. 